\title{
Yayılmacı yabancı böcek türleri ve önemi
}

\author{
Asiye $\mathrm{UZUN}^{1, *}$, Serdar TEZCAN ${ }^{2}$ \\ ${ }^{1}$ Süleyman Demirel Üniversitesi, Ziraat Fakültesi, Bitki Koruma Bölümü \\ ${ }^{2}$ Ege Üniversitesi, Ziraat Fakültesi, Bitki Koruma Bölümü \\ Geliș Tarihi (Recived Date): 14.04.2017 \\ Kabul Tarihi (Accepted Date): 14.09.2017
}

\section{Özet}

$\mathrm{Bu}$ derlemede dünya biyolojik çeşitliliğinin en önemli konuları arasında yer alan yayılmacı yabancı böcek türleri üzerinde durulmaktadır. Özellikle 19. ve 20. yüzyıllarda artan ve günümüzde en üst düzeyine ulaşan ticaret, taşımacılık, turizm ve gezi amaçlı hareketliliklerin yayılmacı yabancı böcek türlerine etkisine ve bu faktörlerin bu türler açısından önemine dikkat çekilmektedir.

Tütün beyazsineği [Bemisia tabaci (Gennadius, 1889) (Hemiptera: Aleyrodidae)], batı çiçek tripsi [Frankliniella occidentalis (Pergande, 1895) (Thysanoptera: Thripidae)], patates böceği [Leptinotarsa decemlineata (Say, 1824) (Coleoptera: Chrysomelidae)], Liriomyza huidobrensis (Blanchard, 1926) (Diptera: Agromyzidae), turunçgil yaprak galerigüvesi [(Phyllocnistis citrella Stainton, 1856) (Lepidoptera: Gracillariidae)] ve domates güvesi [(Tuta absoluta) (Lepidoptera: Gelechiidae)] gibi türler Türkiye'ye bulaşan yabancı yayılmacı türlerdir.

Yayılmacı yabancı böcek türlerinin yarattıkları olumsuzluklara gensel düzeyden ekosistem düzeyine kadar vurgu yapılarak diğer ülkelerde bu konuda atılan adımlar belirtildikten sonra, Türkiye açısından yapılması gerekenlerin neler olduğu vurgulanmaktadir.

Anahtar kelimeler: Biyolojik çeşitlilik, yayılmacı yabancı böcek türleri

\section{Invasive alien insect species and their importance}

\begin{abstract}
This review puts emphasis on the matter of invasive alien insect species, which is accepted as one of the important subjects of biodiversity. In addition, it is emphasized

* Asiye UZUN, asiyeuzun@sdu.edu.tr, http://orcid.org/0000-0002-4822-4762

Serdar TEZCAN, serdar.tezcan@ gmail.com, http://orcid.org/0000-0003-1980-9291
\end{abstract}


that some factors affect invasive alien insect species and these factors can be listed as trade, transport, tourism and touristic mobility which increased in $19^{\text {th }}$ and $20^{\text {th }}$ centuries and reached the highest point lately. This study points out the effects and importance of these factors on these insect species.

Some insect species namely silver leaf white fly [Bemisia tabaci (Gennadius, 1889) (Hemiptera: Aleyrodidae)], western flower thrips [Frankliniella occidentalis (Pergande, 1895) (Thysanoptera: Thripidae)], Colorado potato beetle [Leptinotarsa decemlineata (Say, 1824) (Coleoptera: Chrysomelidae)], serpentine leaf miner [Liriomyza huidobrensis (Blanchard, 1926) (Diptera: Agromyzidae)], citrus leafminer [(Phyllocnistis citrella Stainton, 1856) (Lepidoptera: Gracillariidae)] and tomato leafminer [(Tuta absoluta) (Lepidoptera: Gelechiidae)] are important invasive alien species distributed in Turkey.

The negativities created by this kind of invasive alien insect species are mentioned in this study and these negativities range from gen level to ecosystem level. Noting the steps taken by other countries concerning the negativities of invasive alien insect species, this study also discusses what kind of cautions or steps can be taken in Turkey on this issue.

Keywords: Biological diversity, invasive alien insect species

\section{Giriş}

Böcekler yaklaşık 400 milyon yıldır dünya üzerinde var olan ve günümüzde bir milyondan fazla tür ile varlıklarını sürdüren canlıların en geniş grubudur. Bugün ülkemizde kayıtlı olan türlerin sayısı 30.000 kadar olsa da, bu sayının 80.000-100.000 arasında olduğu tahmin edilmektedir [1].

Türkiye'deki böceklerin bir kısmı endemik nitelikte olup, sadece Türkiye'de veya Türkiye'nin bir bölge ya da yöresinde dağılım göstermektedir. Diğer türlerin ise daha geniş alanlarda dağılım gösterebilen ve Türkiye'nin yanı sıra çevre ülkelerde de bulunabilen, canlılar arası ilişkiler bütünü içinde dengeyi yakalamış türler olduğu görülür. $\mathrm{Bu}$ türlerden bazıları uyum yeteneklerinin üstünlüğ̈̈ nedeniyle dünyanın hemen hemen tüm ana karalarında yayılmış olan kozmopolit türlerdir. Örneğin karasinek [(Musca domestica Linnaeus, 1758) (Diptera: Muscidae)], şeftali yaprakbiti (Myzus persicae Sulzer, 1776), misir yaprakbiti [Rhopalosiphum maidis (Fitch, 1856) (Hemiptera: Aphididae)], sarmaşık kabuklubiti [Aspidiotus nerii Bouché, 1833 (Hemiptera: Diaspididae)] bunlardan birkaçıdır. Yüz milyonlarca yıldır süren ekolojik ilişkiler bütünü kapsamında bu türler dengeyi yakalamış ve günümüze ulaşmıştır.

Özellikle 19. ve 20. yüzyıllarda artan ve günümüzde en üst düzeyine ulaşan ticaret, taşımacılık, turizm ve gezi amaçlı hareketlilikler, insanlarla birlikte bitkiler, karasal ve sucul omurgasızlar, omurgalılar, deniz canlıları başta olmak üzere mikroorganizma ve diğer canlıların ve cansız maddelerin hareketliliğini de arttırmıştır. Bu küresel düzeydeki hareketlilik kapsamında diğer canlılar yanında böcek türleri de hızla yayılmaya başlamış ve yerli tür olarak yayılış gösterdikleri, milyonlarca yıldır bulundukları alanların dişına ulaşarak yabancı tür durumuna gelmişlerdir [1]. Yayılmacı yabanc1 zararlılar ve patojenler, süs bitkisi ve odun ham maddesi ticareti ile 
bulundukları alanlardan başka alanlara taşınmışlardır [2, 3]. Yerli türlerin yabancı tür durumuna gelişlerinde insanların bilinçsiz ve farkında olmadan gerçekleşen hareketlerinin yanı sıra özellikle tarım, ormancılık, balıkçılık alanlarında üretim materyali ve hayvanlar için besin maddesi olarak kullanılmalarının ve dıș alımının büyük rolü olduğu bilinmektedir. Başlangıçta sorun olabileceği öngörülmemesine rağmen biyolojik savaş etmenlerinin yeni alanlara insan tarafından istenerek taşınması, zaman içinde önemli sorunlar yaratabilmiştir. 1920 yılında Fiji'de yerli tür olan Levuana iridescens Bethune-Baker, 1906 (Lepidoptera: Zygaenidae)'in baskılanmas1 için salınan Bessa remota (Aldrich, 1925) (Diptera: Tachinidae)'nın hedef dişı tür olan Heteropan dolens Druce, 1888 (Lepidoptera: Zygaenidae)'in yok olmasina neden olduğu düşünülmektedir [4]. Epiphyas postvittana (Walker, 1863) (Lepidoptera: Tortricidae)'yı baskı altına almak için Avustralya'dan Yeni Zelanda'ya Trigonospila brevifacies (Hardy, 1934) (Diptera: Tachinidae) türü getirilmiştir. Bu türün yerli türlerin populasyonlarını ve onların parazitoitlerini etkilediğinden şüphelenilmektedir. Kır tırtılı [Lymantria dispar (Linnaeus, 1758) (Lepidoptera: Erebidae)] zararını önlemek için 1906' da Kuzey Amerika'ya getirilerek salınan Compsilura concinnata (Meigen, 1824) (Diptera: Tachinidae)'nın salımından kısa süre sonra birkaç yerli kelebek türünün azalmasına neden olduğu belirtilmektedir. Hawai'de Coleotichus blackburniae White, 1881 (Hemiptera: Scutelleridae) türünün, biyolojik savaş için kullanılan parazitoitlerden ziyade kazara giren yumurta predatörlerinden dolayı azaldığı bildirilmektedir [5]. Bezelye yaprakbiti [Acyrthosiphon pisum (Harris, 1776) (Hemiptera: Aphididae)]'nin zararını önlemek için Kuzey Amerika'ya getirilen egzotik parazitoit tür Aphidius ervi Haliday, 1834 (Hymenoptera: Braconidae)'nin yerli parazitoit tür olan Praon pequadorum Viereck, 1912 (Hymenoptera: Braconidae) 'un azalmasına neden olduğu belirtilmektedir [6].

Bu konuda özellikle ada ülkelerinde 19. yüzyıldan bu yana yaşanan ciddi çevresel sorunlar karantina önlemlerinin alınmasını gündeme getirerek bu yayılmanın hızını kesmeyi amaçlasa da, sorunun önemi günümüzde de artarak sürmektedir. Özellikle konunun öneminin ayırdında olmayan ülkelerin göstermelik karantina uygulamaları ne yazık ki çoğu zaman beklenen yararı sağlayamamaktadır.

Bir başka ülkeye ya da bölgeye çoğunlukla havaalanları, yoğun trafiğe sahip uluslararası yollar, büyük şehirler, su kaynakları ve su ulaşım yolları üzerinden ulaşan yabancı nitelikteki türler, uyum güçleri düşükse yeni girdikleri çevreye uyum sağlayamayarak bir süre sonra ölebilmekte ve yeni coğrafi alanda yaşama ve yayılma şansı bulamamaktadir.

Eğer yabancı türün morfolojik, biyolojik, fizyolojik, genetik ve diğer özelliklerine bağlı olarak uyum gücü yüksekse, bu kez yeni geldiği çevreye hızla uyum sağlayarak yaşamaya, çoğalmaya ve canlılar arası ilişkileri ve dengeleri kendi lehine bozarak doğal bulunma alanından daha saldırgan ve ele geçirici bir tek yönlü denge kurma eğilimine girmekte ve yayılmacı bir tür haline gelebilmektedir [7]. Bu özellikleriyle yabancı türlerle, yayılmacı ve baskı kurucu yabancı türleri ayırmak mümkün olmaktadır. $\mathrm{O}$ halde yayılmacı yabancı tür dendiğinde diğer türler yanında çevresel faktörlerle de güçlü bir etkileşim içinde olan türler anlaşılmaktadır. Bu türler insan, hayvan ve bitki sağlığı açısından çoğu zaman doğrudan ya da dolaylı olarak zarara yol açmakta, bu zararın ekonomik boyutu çoğunlukla yüksek olmakta ve gen havuzlarından, bireylere, populasyonlara ve ekosistemlere kadar etkilerini gösterip, bulunduğu ortamı yıkıma götürebilen türler anlaşılmaktadır. Kısacası 
başka bir coğrafi alandan gelen bir türün yayılmacı ve yıkıcı bir durum alabilmesi için sırasıyla coğrafi, çevresel, üreme engellerini aşıp, yayılmacı bir özellik göstermesi gerekir. Yayılmacı nitelikteki yabancı türlerin bu şekildeki yıkıcı ve denge bozucu özellikleri bazen çok kısa süre sonra ortaya çıkarken, bazen de yılların geçmesi gerekmektedir. Bu durumda canlı tür ile çevre faktörlerinin etkileşiminin önemi göz ardı edilmemelidir.

Yeni girdiği alanın iklim faktörleri başta olmak üzere, besin çeşitliliği ve uygunluğu ile diğer türlerin özellikleri ve özellikle doğal düşmanların durumu, bu konuda belirleyici olan ve öne çıkan etkenlerdir. Ayrıca türlerin biyolojik ve fizyolojik özelliklerinin de dikkate alınması gerekir. Üreme kapasitesinin yüksekliği göz ardı edilmemelidir.

Zaman içinde yangın, volkanik faaliyetler, deprem, kasırga gibi doğal kökenli ya da kentleşme, tarımsal ve ormancılık kaynaklı uygulamalar ve endüstriyel alandaki kararlar doğrultusunda da doğada önemli değişiklikler ortaya çıkarak bu türlerin yayılmacı nitelik göstermesi için uygun bir ortam insan tarafından yaratılabilmektedir.

İşte bu faktörlerin birlikte etkisi sonucunda yayılmacı nitelik kazanan yabancı tür, yeni girdiği ortamda hızla çoğalarak dengeleri bozmaya başlamaktadır. Kısa sürede tarım ve orman alanlarında yarattığı olumsuz etkiler zincirleme olarak tüm ekosistemleri ve tüm ilişkiler bütününü etkileyerek olumsuz sonuçlarını yaratmaktadır. Örneğin asit yağmurlarıyla Avrupa'da başlayan olumsuz etkiler, orman ve tarım alanlarının yanı sıra tüm yaşam alanlarını kapsamış, ormanlarda başlayan ölümler karasal ve sucul alanlar da dahil olmak üzere kıta genelinde etkisini göstermiştir. Habitat kayıpları, biyolojik çeşitliliğin azalması ve ekosistemlerde ortaya çıkan olumsuzluklar hala çözüm bekleyen sorunlar olarak ortada durmaktadır. Küresel ısınma ile birlikte bu durum dünya ölçeğinde bir sorun olarak kendini göstermiş olup, sorunun bu ölçüdeki büyüklüğü tüm dünyada daha dikkatli olmayı zorunlu kılmıştır.

\section{Yayılmacı türlerin yarattıkları olumsuzluklar}

Yayılmacı nitelik gösteren yabancı böcek türlerinin yaratacakları olumsuz etkiler gensel düzeyden ekosistem düzeyine kadar değişik şekillerdeki ekolojik ilişkiler bütününde kendini gösterebilmektedir. Bu konular aşağıda ana başlıklar halinde ele alınmıştır:

\subsection{Gen havuzlarına kirletici etkiler}

Yeni veya değişen çevresel koşullara uyum için bir populasyonun kapasitesini ve yayılmacı olabilme potansiyelini belirlemede, ortaya çıkan genetik değişiklikler önemli bir rol oynamaktadır $[8,9]$. Birbiri içine giren alttürlerde genetiksel olarak ortaya çıkan sorunlar dünyada olduğu gibi Türkiye'de de dikkat çekmekte ve önem taşımaktadır. Örneğin farklı balarısı [Apis mellifera Linnaeus, 1758 (Hymenoptera: Apidae)] alttürleri ya da ırklarının arıcılar yani insanlar tarafından yapılan gezgin arıcılık çalışmalarıyla taşınması, alttürlere ait genetiksel havuzun kirlenmesini beraberinde getirmekte ve o alttüre ait saf nitelikte gen havuzu kalmamaktadır. Benzeri tehlikeler üstün tozlayıcılıkları nedeniyle tercih edilen ve insan etkisiyle yaygınlaştırılan toprak yabanarıs1 [Bombus terrestris Linnaeus, 1758 (Hymenoptera: Apidae)]'nın alttürleri ve etkileşen diğer alttürler için de söz konusudur [10]. 


\subsection{Yerli bitki topluluklarına doğrudan etkiler}

Yayılmacı nitelik gösteren böcek türleri herhangi bir bölgeye girdiğinde hıla yayılarak konukçuları için ciddi zarar meydana getirmeye başlamaktadır. Örneğin Avrupa'dan 19. yüzyılda Amerika'ya bulaşan kır tırtılı [Lymantria dispar (Linnaeus, 1758) (Lepidoptera: Erebidae)], başta meşe olmak üzere geniş yapraklı ağaçlarda o kadar önemli zarar yapmıştır ki, yeni yapraklanmaların meydana gelmesine firsat vermeyişi nedeniyle meşe ormanlarında yoğun ölümlere yol açmıştır [7].

Bazı durumda o bölgeye giren yayılmacı türler, özellikle uygun konukçu olarak buldukları, o bölge için endemik nitelikteki bitki türleri üzerinde de önemli zararlar meydana getirebilmektedir. Örneğin kaynanadili [Opuntia Miller, 1754 (Caryophyllales: Cactaceae)] cinsine bağlı kaktüs türleriyle biyolojik savaş amaciyla 1950'li yıllarda Karayip Adaları'na sokulan Cactoblastis cactorum (Berg, 1885) (Lepidoptera: Pyralidae) isimli böcek türü geçen zaman içinde Meksika kıyıları ve Florida'da hızla yayılmış ve Opuntia cinsine bağlı türler için önemli bir genetik çeşitlilik ve endemizm merkezi olan bu yöredeki bitkilerin soyunu tehlike altına sokmuştur [11].

Bir başka örnek ise Galapagos Adaları'ndan verilebilir. Galapagos Adaları'na giren torbalı koşnil [Icerya purchasi Maskell, 1878 (Hemiptera: Margarodidae)] yerli flora içinde yer alan pek çok bitki türünü ciddi şekilde tehdit etmeye başlamış [7] ve bunun üzerine doğal düşmanı olan kardinal böceği [Rodolia cardinalis (Mulsant, 1850) (Coleoptera: Coccinellidae)] salınarak olumsuz etki azaltılmaya çalışılmıştır.

\subsection{Yerli bitki topluluklarına dolaylı etkiler}

Yayılmacı türlerin doğrudan etkilerinin ardından dolaylı etkiler de görülmeye başlamaktadır. Örneğin yayılmacı türlerin konukçularını öldürmeleri ve azaltmaları sonucunda, ortaya çıkan ekolojik boşluktan diğer yerli bitki toplulukları da dolaylı olarak etkilenmektedir. Örneğin Kuzey Amerika'da Lymantria dispar'ın meşe yapraklarında oburca beslenmesi, meşe tohumu üretimini ve genç meşe fỉdan gelişimini doğal akışı içinde olumsuz yönde etkilemiş ve bu durum karışık orman ekosisteminde bitki tür ve çeşitlerinin biyolojik zenginliğini olumsuz yönde etkileyerek dengeleri istenmeyen doğrultuda değiştirmiştir [12].

\subsection{Yerli faunaya doğrudan ve dolaylı etkiler}

Yayılmacı bir türün bir bölgeye girişi yerli fauna için de doğrudan ve dolaylı yönlerden etki gösterebilir. Doğrudan etki yabancı ve yerli türler arasındaki etkileşim sonucu şekillenir ki bu etkileşim sonucunda genellikle yabancı tür lehine bir gelişim ortaya çıkmaktadır [13]. Olumsuz yönde etkilenen yerli türler hızla azalma içine girmekte ve özellikle yerli türlerin doğal düşmanları da besin bulamayacağı için besin zincirinin sonraki halkaları da bu durumdan olumsuz yönde etkilenmekte ve böylece ekosistemde çöküş hızlanmaktadır. Örneğin Galapagos Adaları'nda Icerya purchasi'nin bitkilerde yol açtığı zarar, bu bitkilerle beslenen Lepidoptera takımına bağlı diğer türlerin konukçularının yok olmasına yol açmış ve bu durumdan onların doğal düşmanları da olumsuz yönde etkilenmiştir [14]. Özellikle Asya kökenli bir gelinböceği türü olan Harmonia axyridis (Pallas, 1773) (Coleoptera: Coccinellidae)'in Avrupa'da hizla yayılım göstererek biyolojik çeşitlilik üzerinde olumsuz etkiler göstermesi, konu uzmanlarını önemli şekilde tedirgin etmektedir [15]. 


\subsection{Hastalıkların yayılması üzerine etkiler}

$\mathrm{Bu}$ etkiler farklı organizma grupları üzerinde farklı şekillerde ortaya çıkarak önemli sorunlar yaratabilir.

Bitki hastalıklarının yayılması üzerine etkilere bakıldığında yayılmacı nitelik gösteren etmenlerin, doğrudan ya da dolaylı olarak bitki hastalıklarının yayılması üzerinde rol aldığı görülmektedir. Doğrudan etki vektör nitelikteki türlerin artan populasyonları sonucunda gerçekleşmektedir. Avrupa'da görülen Karaağaç ölümü hastalığıyla, bu hastalığın vektörü olan karaağaç küçük kabukböceği [Scolytus multistriatus (Marsham, 1802) (Coleoptera: Curculionidae)] populasyonu arasında bu yönde bir ilişki bulunmaktadır [7]. Dolaylı etkide ise ekosistemlerde yukarıda örneklerle aktarıldığı gibi değişiklikler olduğunda dengeler bozulmakta ve önceden bulunsa da olumsuz etkisini gösteremeyen pek çok hastalık etmeni etkin hale gelerek zayıflayan ekosistemi çökertme yolunda belirleyici olabilmektedir.

Hayvan hastalıklarının yayılması üzerine etkiler ele alındığında bazı sivrisinek türlerinin hayvan hastalıklarının vektörlüğünü yaptığı görülür. Örneğin kuş sıtması hastalığının vektörü olan Culex quinquefasciatus Say, 1823 (Diptera: Culicidae) türünün yeni Zelanda'ya girişi ve yayılmasıyla bu hastalığın konukçularındaki artışı arasında bir ilişki bulunmuştur [16]. Benzeri etki çok sayıda tür için belirtilmektedir.

İnsan hastalıklarının yayılması üzerine etkiler incelendiğinde, yayılmacı özellikteki böcek türlerinin girişiyle birlikte insan hastalıklarının böcek yayılış alanına paralel olarak arttığı görülmektedir. Sitmanın sivrisinek yayılışıyla ilişkisi eskiden beri bilinmektedir ve küresel isınmayla birlikte kuzey enlemlerdeki ülkelerde de sitmanın yayılmasının beklenişinin kökeninde bu gerçek yer almaktadır. Ayrıca başta alerjik tepkiler olmak üzere pek çok hastalık da böcekler ve diğer canlı organizmalar içinde yer alan yayılıcı yabancı türlerin artışıla birlikte artma göstermektedir.

\subsection{Diğer etkiler:}

Yayılmacı yabancı böcek türleriyle birlikte bitkiler başta olmak üzere, bakteri, fungus ve diğer etmenlerin yol açtıkları sorunlar dünyada her geçen gün artmakta; biyolojik dengeler başta olmak üzere tüm yaşam bu bozulmalardan zarar görmektedir.

Ortaya çıkan zararların ekonomik boyutları ise yıldan yıla değişmekle birlikte çok büyüktür. Bu durum sosyal sorunlarla birlikte, açlık ve sefalet gibi diğer sıkıntıları da beraberinde getirmektedir.

\section{Yayılmacı yabancı böcek türleri ve Türkiye}

Bu çok önemli konuya Türkiye'nin de gereği şekilde eğilmesi bir zorunluluktur. Bilindiği gibi Türkiye, Avrupa, Asya ve Afrika kıtalarının kesişim noktasında yer almakta ve çevresinin büyük bir kısmının denizlerle kaplı olması nedeniyle ulaşım yollarının da odağında bulunmaktadır. Ayrıca sahip olduğu farklı yeryüzü şekilleri ve zengin bitki örtüsü biyolojik çeşitlilik açısından özel bir durum yaratmaktadır. Bu durum bu özel coğrafyaya ulaşan yayılmacı nitelikteki yabancı türlerin yaşama şansı bulmasını ve varlığını sürdürme olasılığını arttırmaktadır. Tütün beyazsineği [Bemisia tabaci (Gennadius, 1889) (Hemiptera: Aleyrodidae)], batı çiçek tripsi [Frankliniella occidentalis (Pergande, 1895) (Thysanoptera: Thripidae)], patates böceği [Leptinotarsa 
decemlineata (Say, 1824) (Coleoptera: Chrysomelidae)] ve Liriomyza huidobrensis (Blanchard, 1926) (Diptera: Agromyzidae) gibi DAISIE (Delivering Alien Invasive Species Inventories for Europe) [17] kaynaklarına göre Avrupa'nın en kötü yayılmacı türleri ne yazık ki son 50 yılda Türkiye'ye de bulaşarak hızla yayılmıştır. Örneğin patates böceği Edirne'den 1963 yılında; Amerikan beyazkelebeği [Hyphantria cunea (Drury, 1773) (Lepidoptera: Erebidae)] Edirne, İstanbul ve Tekirdağ'dan 1975 y1lında [18]; turunçgil yaprak galerigüvesi [(Phyllocnistis citrella Stainton, 1856) (Lepidoptera: Gracillariidae)] Adana'dan 1994 yılında [19]; palmiye kırmızıböceği [(Rhynchophorus ferrugineus) (Oliver, 1790) (Coleoptera: Dryophthoridae)] Mersin'den 2005 y1linda peyzaj amacıyla Türkiye'ye getirilen yaşlı ağaçlarla bulaşmış, aradan geçen 12 yıllık süreç içinde sahil şeridinde yer alan ve giriş yaptığı Mersin'e ek olarak Adana, Antalya, Muğla, Aydın ve İzmir illerinde hızla yayılım göstermiştir. Bunların dışında domates güvesi [(Tuta absoluta) (Lepidoptera: Gelechiidae)] İzmir'den 2009 yılında; yassıbacaklı çam tohum tahtakurusu [Leptoglossus occidentalis (Heidemann, 1910) (Hemiptera: Coreidae)] İstanbul'dan 2009 y1lında [20, 21]; şimşir kurdu [Cydalima perspectalis (Walker, 1859) (Lepidoptera: Crambidae)] İstanbul'dan 2011 yilında [21] Türkiye'ye giriş yaptığı bilinen türlerdir. Ayrıca doğal yayılış alanı Kuzey Amerika olan çınar kaplanı [Corythucha ciliata (Say, 1832) (Hemiptera: Tingidae)] Türkiye'de ilk kez 2007 yılında Bolu İlinden kaydedilmişken, 2014'te Kastamonu'dan bildirilmiş ve 6 yıllık bir süreçte Marmara ve Karadeniz Bölgelerine yayılmıştır [22]. Meşe kaplanı [Corythucha arcuata (Say, 1832) (Hemiptera: Tingidae)] Kuzey Amerika kökenli bir tür olup, Türkiye'de ilk kez 2003 yılında Bolu'da saptanmış ve 2009 yılında Düzce, Zonguldak, Sakarya, Kocaeli, Eskişehir, Ankara, Çankırı ve Bilecik’te; 2010 yılında ise Trabzon'da yayılış gösterdiği belirlenmiştir [23]. Doğal olarak Çin, Japonya ve Kore'de yayılış gösteren turunçgil tekeböceği [Anoplophora chinensis (Forster, 1771) (Coleoptera: Cerambycidae)] 2014 y1lında Şile (İstanbul)'de kaydedilmiş olup, yayılış alanını daha önce bulaştığı diğer ülkeler gibi Türkiye'de de genişletmesi beklenmektedir. [2].

Görüldüğü gibi bu türlerin bazıları tüm Türkiye'ye yayılarak zararını göstermekte, bazıları ise henüz bölgesel olarak yayılış göstererek, yayılış alanlarını yıldan yıla arttırmaktadır. Özellikle doğal düşman ve diğer çevre faktörlerinin baskısıyla birlikte bu türlerin yayılış hızı zaman içinde düşse de, özellikle doğal düşman baskısının yetersizliği durumunda bu yayılış hızla sürmekte ve bunların biyolojileri, yayılışları ortaya konarak zararını önlemek için alınması gerekli önlemler konusunda ayrıntılı çalışmalar yapılmaktadır. Ayrıca karantina önlemleri konusunda da daha dikkatli olunmalidir.

\section{Yayılmacı türlere yönelik ulusal ve uluslararası faaliyetler}

Hayvan ve bitki türlerinin başka alanlara nakledilmesi uygarlıkla ilişkilendirilmekte ve kolonileşme hareketleri de bu konuda önemli rol oynamaktadır. Günümüzde ise 4T olarak adlandırılan "Trade, Transport, Travel, Tourism" yani ticaret, taşımacılık, seyahat ve turizm, tür hareketliliğini oldukça hızlandırmıştır.

On dokuzuncu yüzyılda Avrupa'da birkaç bitki zararlısının girişine bağlı olarak bitki ürünlerin korunması ve bitki zararlılarının girişi ve yayılmasının önlenmesi için bitki karantina önlemlerinin geliştirilmesini gerektirmiştir. Bitkilere hem doğrudan hem de dolaylı olarak zarar veren organizmaları ele alan, bu zararlıları kontrol etmek için 
destekleyici önlemlerin alınması amacıyla Uluslararası Bitki Koruma Anlaşması (IPPC) yapılmıştır.

Türkiye'de yabancı türlerle mücadele konusunda çalışmalar devam etmektedir. Ulusal Biyolojik Çeşitlilik Stratejisi ve Eylem Planı Taslağı kapsamında 2007 yılında yabancı türlerle mücadele konusunda düzenlemeler yapılmıştır. Mevzuatta doğaya yabancı türlerin bırakılamayacağı belirtilmiş ve zararlı olan yabancı türlerle ilgili hükümler getirilmiştir. Örneğin "Av ve Yaban Hayvanlarının ve Yaşam Alanlarının Korunması, Zararlılarıyla Mücadele Usul ve Esasları Hakkında Yönetmelik"in 53. maddesi uyarınca "Herhangi bir nedenle yabancı veya yayılmacı bir türün kendi habitatından farklı bir doğal yaşam ortamına girmesi ve bu alanda hızlı bir şekilde üreyerek, yayılışını genişletmesinden dolayı; habitatın yerli bitki ve hayvan türlerine, tarım arazilerine, evcil hayvanlara ve insanlara olumlu ve olumsuz ekonomik ve ekolojik etkileri Doğa Koruma ve Milli Parklar Genel Müdürlüğü'nün koordinasyonunda araştırılmaktadır. $\mathrm{Bu}$ yabancı türlerden, habitatın yerli bitki ve hayvan türlerine, tarım arazilerine, evcil hayvanlara, insanlara, ekonomiye ve ekolojiye olumsuz etkisi olanlarla mücadelenin, bu türlerin biyolojik özellikleri dikkate alınarak Genel Müdürlügün belirlediği usul ve esaslar çerçevesinde il müdürlüğü tarafından yapılacağı ya da yaptırılacağı belirtilmektedir. Gerçek ve tüzel kişilerin neden olduğu durumlarda 4915 sayılı Kara Avcılığı Kanununun 26. maddesi ile 2872 sayılı Çevre Kanununun 28. maddesi hükümlerine göre işlem yapılacağı ifade edilmektedir.

Avrupa'da da yabancı yayılmacı tür sorunlarından omurgasızların korunması için stratejilerden söz edilmektedir. Küresel Yayılmacı Tür Programı, sorun olan türleri tahmin etme, kontrol etme ve önlemeyi sağlayan ölçütler getirmiştir. Uluslararası Doğa Koruma Birliği (IUCN) yayılmacı türlerin girişini önlemenin en ucuz, en çok tercih edilen ve öncelik verilmesi gereken bir yol olduğunu vurgulamaktadır. Bern Konvensiyonu kapsamında Avrupa için yayılmacı tür stratejisi geliştirilmiş [24] ve arzu edilmeyen böcek yayılımlarını önleyerek ekonomik kayıplardan kaçınmak için bitki üreten işletmeciler ve taşıyıcılar için bilimsel bitki sağlığı önerileri ve düzenlemeler hazırlamış olup, bu düzenlemeler ekonomik kayıplara neden olan yayılmacı böceklerin ülkelere giriş ve çıkışlarını kontrol etmek için kullanılmaktadır.

Küresel Yayılmacı Türler Veritabanı [The Global Invasive Species Database (GISD)] bütün ekosistemlerde mikroorganizmalardan bitki ve hayvanlara kadar bütün canlı gruplarını kapsayan ve doğal ekosistem ve yerli biyoçeşitliliği tehdit eden yayılmacı yabancı türlere odaklanmaktadır. Türlerle ilgili bilgiler, dünyadaki uzman katılımcılar tarafından sağlanmakta [1] ve yayılmacı yabancı türler hakkında bilincin arttırılması ve bunlarla etkin mücadele yapılması amaçlanmaktadır. Uluslararası Doğa Koruma Birliği (IUCN)'nin Tür Yaşam Komisyonu [(Species Survival Commission) (SSC)]'nun Yayılmacı Tür Uzman Grubu (ISSG) tarafindan düzenlemeler yapılmaktadır. Yayılmacı Türler Uzman Grubu (ISSG), Küresel yayılmacı Türler Programı [Global Invasive Species Programme (GISP)] ile yayılmacı türler konusunda küresel bir çalışma başlatmıştır.

Buna göre Küresel Yayılmacı Türler Programı kapsamında bilgi değişimi ve bilinci arttırarak politika geliştirip, yayılmacı türlerin küresel tehditleriyle mücadele edilmesi amaçlanmıştır. Bu uluslararası program yasal olarak ortak dört kurucu kuruluş olan CABI, IUCN, The Nature Conservancy (TNC) ve the South African National Biodiversity Institute (SANBI) arasında yürütülmektedir. Yayılmacı türler üzerine ilk 
uluslararası toplantı 1996'da Norveç (Trondheim)'te yapılmıştır. Küresel Yayılmacı Türler Programı yayılmacı türlerin küresel düzeyde neden oldukları tehditlere karşı farkındalığı arttırma ve veri yapılandırılmasında özellikle Biyolojik Çeşitlilik Sözleşmesi gereği yayılmacı türlerle ilişkili uluslararası anlaşmalara destek sağlamayı amaçlamakta ve 2020'ye kadar ülkelerin çoğunun ulusal biyogüvenlik stratejileri ve hareket planlarını uygulamak için politikalar oluşturmalarını hedeflemektedir.

Yayılmacı Türler Uzman Grubu, Uluslararası Doğa Koruma Birliği (IUCN) çatıs1 altında görev yapan Türlerin Yaşam Komisyonu (SSC)'nun uzman grubudur. Bu grubun amacı yabancı istilalar hakkında bilinci ve bunları önleme, kontrol etme ve yok etme yollarını arttırmak ve yerli tür ve doğal ekosistemlere tehditlerini azaltmaktır.

\section{Sonuç ve öneriler}

Yukarıdaki örneklerde de görüldüğ̈̈ gibi sorun ulusal değil uluslararası nitelikte bir sorundur ve çözümü de bu gerçek göz önüne alınarak sağlanmalıdır. Yayılmacı niteliği uluslararası düzeyde izlenen türlerin, ülkeye girişine engel olacak önlemlerin dinamik şekilde alınması atılacak adımların ilkidir. Pek çok tür çevre ülkelerde ya da ticari ilişki içinde bulunulan ülkelerdeki durumlarıyla izlenmeli ve bu ülkelere karşı karantina önlemleri daha ciddi şekilde uygulanmalıdır. Örneğin EPPO (European and Mediterranean Plant Protection Organization) tarafından yürütülen uluslararas1 çalışmalarda yayılmacı türlerin belirlenip listelenmesine, risk analizlerinin yapılmasına, ülkeler arası bilgi alışverişinin yeni ülkeler ve coğrafi bölgelerle, konukçular, araştırma ve tanılama yöntemleri düzeyinde gerçekleştirilmesine ve böylece o türün yönetimine yönelik işlemlerin uluslararası bilgi alışverişi ve yardımlaşma ile sağlanmasına çalışılmaktadır. Yabancı yayılmacı türlerden hemen müdahalede bulunulması gerekenler kara listeye, hemen müdahaleyi gerektirmeyenler gri listeye ve zaman içinde doğal dengeyle bütünleşenler ise izleme listesine alınarak gözden kaçırılmamaktadır. Avrupa Birliği işte bu nedenle sorunun önemini göz önüne alarak politik sınırlar ötesinde konuya eğilmekte ve önceki karar ve uygulamalarını tekrar gözden geçirerek erken uyarı ve hızlı eylem sistemi üzerinde durmaktadır. Bu konudaki bazı önemli veri tabanları aracılığıyla ayrıntılı bilgi kaynaklarına [25-30] ulaşılabilmesi mümkündür.

Özellikle yayılmacı nitelik gösteren yabancı türlerin bulaşmalarının önlenmesi, bulaşma olduysa bu konuda erken uyarı sistemini devreye sokarak alınması gereken olası önlemlerin belirlenmesi, belirlenen önlemlerin yaşama sokularak acil olarak uygulanması ve bu sırada da çevre sağlığını ve dengeleri tehlikeye atmayacak adımların atılması büyük önem taşımaktadır.

Bütünleştirilmiş risk haritaları ve ayrıntılı değerlendimeler yayılmacı türlere denetim programları sağlamak için kapsamlı bilgi gerektirmektedir. Yayılmacı türlerin yönetiminde stratejik ve taktiksel kararların alınabilmesi aşamasında, zararlı ve hastalık etmenleri hakkında bilgi sahibi olabilmek için "zararlı risk haritaları" oluşturularak, yayılmacı etmenlerin biyolojisi ve ekolojisi göz önünde bulundurulmakta ve giriş yapabileceği alanlar ve yayılış gösterebileceği yöreler görsel olarak ortaya koyulup, buna bağlı olarak önlemler alınabilmektedir [3].

Ülke içinde de benzeri önlemlerin titizlikle alınmasında, gerek yayılmaların önlenmesi, gerekse yayılma hızının yavaşlatılması açısından büyük yarar vardır. Başta üretim 
materyali ve ürünler olmak üzere bulaşmalara konu olabilecek materyalin ülkeye giriş ve çıkışında dikkatli olunması ilk gerekliliktir. Her ne kadar biyolojik çeşitlilik strateji ve eylem planında bu konuya değinilse de, mevzuatta yer alan yasal yükümlülüklerin de ilgili kurumlarca eksiksiz olarak yerine getirilmesinde zorunluluk vardır. Tüm bunlara karşın yine de bulaşmalar oluyorsa acilen gerekli işlemler yapılarak o yayılmacı türün daha geniş alanlara yayılmasını önleyecek önlemler alınmalı, biyolojik kirlilik unsuru olan yayılmacı yabancı türlerin önüne geçilmelidir. Unutulmamalıdır ki bu konu dünyadaki tüm canlıların geleceğini ilgilendiren bir konudur. Ticaret, taşımacılık, turizm ve gezi amaçlı hareketlilik arttıkça ve insanın bilgisizlik ve duyarsızlığı devam ettikçe daha da artacak olan önemli bir sorundur. Günümüzde insanlığın tartıştığı ana konulardan biri olan küresel ısınma konusu da yayılmacı yabancı böcek türleriyle doğrudan ilişkili bir konu olup, olumsuz sonuçları en aza indirmek için birlikte değerlendirilmeli ve önlemler buna göre alınmalıdır. Ayrıca insan kaynaklı doğa tahribi, toprak kullanım yaklaşımlarındaki değişimler, su sıkıntısı gibi sorunlar konunun önemini daha da arttırmakta ve çözümü her geçen gün zorlaştırmaktadır.

Türkiye'nin bu konunun çözümüne ne kadar hazırlıklı olduğu önemlidir. Özellikle yayılmacı türler konusundaki uzman potansiyelini gözden geçirmesini ve eksik alanlarla ilgili uzmanları acilen yetiştirmesini, konunun temelini oluşturan doğaya yönelik bilgilerin yeterli olup olmadığını değerlendirerek özellikle yayılmacı yabancı tüm canlı grupları için Türkiye'ye özgü listelerin hazırlanmasında gecikip gecikmediğini sorgulamasının yerinde olacağı düşünülmektedir. Ayrıca Bakanlık ve üniversitelerin bu konuyu araştırmak üzere merkez, koleksiyon, herbaryum ve müzeler gibi birimler oluşturarak altyapı oluşturmasının, eğitim programları yürütmesinin ve elde edeceği bilgileri de en kısa zamanda toplumla paylaşmasının uygun olacağı düşünülmektedir. $\mathrm{Bu}$ konularda eğer gerekenler yapılmayacak olursa sonuçlarına da katlamak durumunda kalacağımızı peşinen belirtmekte yarar bulunmaktadır.

\section{Kaynaklar}

[1] Gözcelioğlu, B., Yabancı Türler ve Biyolojik İstila, Bilim ve Teknik, 84-85, (2009).

[2] Hizal, E., Arslangündoğdu, Z., Göç, A., ve Ak, M., The new record for Turkish invasive alien insect fauna Anoplophora chinensis (Forster, 1771) (Coleoptera: Cerambycidae), İstanbul Üniversitesi Orman Fakültesi Dergisi, 65, 7-10, (2015).

[3] Oskay, F., Lehtijärvi, A., Doğmuş-Lehtijärvi, H. T., ve Aday Kaya, A. G., Değişen dünya'da orman patojenleri; yabanc1 istilacı türler ve ülkemiz ormancılığı üzerindeki tehditler, Türkiye II. Orman Entomolojisi ve Patolojisi Sempozyumu, Antalya, 475-479, (2014).

[4] Kuris, A. M., Did biological control cause extinction of the coconut moth, Levuana iridescens, in Fidji?, Biological Invasions, 5, 131-141, (2003).

[5] Johnson, M. T., Follett, P. A., Taylor, A. D., and Jones, V. P., Impacts of biological control and invasive species on a non-target native Hawaiian insect, Oecologia, 142, 529-540, (2005).

[6] Schellhorn, N.A., Kuhman, T. R., Olson, A. C., and Ives, A. R., Competition between native and introduced parasitoids of aphids: non-target effects and biological control, Ecology, 83, 2745-2757, (2002). 
[7] Kenis, M., Auger-Rozenberg, M-A., Roques, A., Timms, L., Pere. C., J.W. Cock. M., Settele. J., Augustin. S., and Lopez-Vaamonde. C., Ecological effects of invasive alien insects, Biological Invasions, 11, 21-45, (2008).

[8] Roman, J. and Darling, J. A., Paradox lost: genetic diversity and the success of aquatic invasions, TRENDS in Ecology and Evolution, 22, 9, 454-464, (2007).

[9] Sakai, A. K., Allendorf, F. W., Holt, J. S., Lodge, D. M., Molofsky, J., With, K. A., Baughman, S., Cabin, R. J., Cohen, J. E., Ellstrand, N. C., McCauley, D. E., O'Neil, P., Parker, I. M., Thompson, J. N., and Weller, S.G., The Population Biology of Invasive Species, Annual Review of Ecology and Systematics, 32, 305-332, (2001).

[10] Gösterit, A., ve Gürel, F., Bombus terrestris (Hymenoptera: Apidae) Arılarının Yayılmasının Ekosistem Üzerine Etkileri,. Uludağ Arıcılık Dergisi, 5, 115-121, (2005).

[11] Perez-Sandi, C. M., Addressing the threat of Cactoblastis cactorum (Lepidoptera: Pyralidae), to Opuntia in Mexico, Fla Entomology, 84, 499-502, (2001).

[12] Lovett, G. M., Canham, C. D., Arthur, M. A., Weathers, K. C., and Fitzhugh, R. D., Forest ecosystem responses to exotic pests and pathogens in eastern North America, Bioscience, 56, 395-405, (2006).

[13] Reitz, S. R., and Trumble, J. T., Competitive displacement among insects and arachnids, Annual Review of Entomology, 47, 435-465, (2002).

[14] Roque-Albelo, L., Population decline of Galápagos endemic Lepidoptera on Volcano Alcedo (Isabela Island, Galápagos Islands, Ecuador): an effect of the introduction of the cottony cushion scale?, Bulletin de l' Institut Royal des Sciences Naturelles de Belgique, Entomologie, 73, 1-4, (2003).

[15] Hoogendoorn ,M., Heimpel, G. E., Indirect interactions between an introduced and a native ladybird beetle species mediated by a shared parasitoid, Biological Control, 25, 224-230, (2002).

[16] Tompkins, D. M., and Gleeson, D. M., Relationship between avian malaria distribution and an exotic invasive mosquito in New Zealand, Journal of the Royal Society of New Zealand, 36, 51-62, (2006).

[17] BFIS (The Belgian Forum on Invasive Species), http://ias.biodiversity.be, (20.05.2017).

[18] Anonymous, Zirai Mücadele Programı ve Uygulama Prensipleri, Tarım ve Orman Bakanlığı Koruma ve Kontrol Genel Müdürlüğü Yayınları, Ankara, (1991).

[19] Uygun, N., Karaca, İ., Aytaş, M., Yumruktepe, R., Yiğit, A., Ulusoy, R., Kersting, U., Tekeli N. Z. ve Canhilal, R., Turunçgillerde zararlı Turunçgil yaprak galeri güvesi, Phyllocnistis citrella Stainton (Lepidoptera, Gracillaridae), Türkiye Entomoloji Dergisi, 19 (4), 247-252, (1995).

[20] Arslangündoğdu, Z. ve Hizal, E., The Western Conifer Seed Bug, Leptoglossus (Heidemann. 1910), recorded in Turkey (Heteroptera: Coreidae), Zoology in the Middle East, 50, 138-139, (2010).

[21] Hizal. E., Two Invasive Alien Insect Species, Leptoglossus occidentalis (Heteroptera: Coreidae) and Cydalima perspectalis (Lepidoptera: Crambidae), and their distribution and host plants in Istanbul province, Turkey, Florida Entomological Society, 95, 344-349, (2012).

[22] Kezik, U., ve Eroğlu, M., Ülkemizin yeni istilacı türü, çınar ağkanatlı tahtakurusu, Corythucha ciliata (Say, 1832) (Hemiptera: Tingidae)'nın Doğu 
Karadeniz bölgesindeki zararı, Türkiye II. Orman Entomolojisi ve Patolojisi Sempozyumu, Antalya, 234-238, (2014).

[23] Küçükbasmacı, İ., Kastamonu'dan iki yeni istilacı tür kaydı: Corythucha arcuata (Say) (Heteroptera: Tingidae) ve Corythucha ciliata (Say) (Heteroptera: Tingidae), Türkiye II. Orman Entomolojisi ve Patolojisi Sempozyumu, Antalya, 361-362, (2014).

[24] Genovesi, P. and Shine, C., European Strategy on Invasive Alien Species, 58, Council of Europea Publishing, Wasselone, France, (2004).

[25] BFIS (The Belgian Forum on Invasive Species), http://ias.biodiversity.be, (20.05.2017).

[26] DAISIE (Delivering Alien Invasive Species Inventories for Europe), http://www.europe-aliens.org/default.do, (20.05.2017).

[27] EASIN (European Alien Species Information Network), http://easin.jrc.ec.europa.eu/, (20.05.2017).

[28] GISD (Global Invasive Species Database), http://www.issg.org/database, (20.05.2017).

[29] IASPMR (Invasive Alien Species Pathway Management Resource), http://acronym.co.nz:8086/, (20.05.2017).

[30] ISC (Invasive Species Compendium), http://www.cabi.org/isc, (20.05.2017). 